\title{
Perspective
}

\section{COVID-19 in Turkey: Lessons Learned}

\author{
Banu Cakir, (1) \\ Department of Public Health, Hacettepe University Faculty of Medicine, Ankara, Turkey
}

\section{ARTICLE INFO}

\section{Article History}

Received 30 April 2020

Accepted 18 May 2020

\section{Keywords}

COVID-19

pandemic

Turkey

epidemiology

\begin{abstract}
Turkey reported its first COVID-19 case on March 10, 2020. We present here the mitigation efforts Turkey has undertaken so far, and also review the lessons learned for future proactive strategies. High number of intensive care unit beds and ventilators, national treatment algorithms, governmental support for free testing and medications, tedious contact-tracing with early detection and isolation of cases together with early shelter-in-place for the elderly and youngsters, and subsequent weekend curfews in selected cities have so far prevented the surge pressure on the health care system. At this phase, Turkey needs to adopt an evidence-based, proactive control system for an effective transition process to normalize the situation. Here, we underline the urgent need for detailed analysis of the national COVID-19 data and propose an epidemiologic investigation framework for better understanding, efficient control, and reliable forecasting of COVID-19 pandemic.
\end{abstract}

(C) 2020 The Authors. Published by Atlantis Press International B.V.

This is an open access article distributed under the CC BY-NC 4.0 license (http://creativecommons.org/licenses/by-nc/4.0/).

\section{INTRODUCTION}

Turkey reported its first COVID-19 case on March 10, 2020 [1,2]. Although a variety of preventive measures had been put in practice at individual and public level starting from mid-January 2020 and were tightened over the course of COVID-19 in Turkey, number of cases has increased rapidly. Turkey has risen to the list of top 10 countries with highest COVID-19 cases globally, within 30 days of the epidemic [1]. In COVID-19 situation reports of the World Health Organization, Turkey appears in the list of countries with community transmission, meaning, there are large number of cases not linked to transmission chains and multiple unrelated clusters in several areas [3].

Controlling the spread of COVID-19 has become the foremost concern of several countries with unprecedented international collaboration and rapid dissemination of emerging scientific evidence over the last 3 months. In this context, Turkey had the opportunity to learn from Chinese and European experience on comparative effectiveness and feasibility of various preventive measures to mitigate the epidemic. We are also fortunate to have high number of hospitals and intensive care unit beds ( 280 and 40 per 100,000 population, respectively), with a well-established critical care system [2,4].

Centralized pandemic-management activities, free testing, prompt hospitalization of moderate-severe cases with adequate stockpile of potential treatment medications in all hospitals, nationwide contact-tracing, quarantine practices, and daily follow up of all contacts through local primary care health workers have been successful so far to keep the healthcare system function without overload, despite the high number of COVID-19 cases ( $n=117,589$ on April 30, 2020) [2].

Two main strategies to combat COVID-19 in Turkey so far have been diverting the majority of resources (including the manpower)

"Email:bcakir@hacettepe.edu.tr; banucakir4@gmail.com to support the accessibility and availability of healthcare services, and asking public to strictly comply with the recommended preventive measures. Table 1 summarizes the various public measures for mitigating COVID-19 [2,5]. Number of new cases started decreasing by the end of April with an increase in those recovered. Daily death numbers ranged between 1 and 126, with a total number of 3174 deaths, on April 30, 2020 (Figure 1). The case-fatality rate showed a steady increase, ranging between $1.02 \%$ and $2.43 \%$, yet, have been relatively low compared with that in other countries with similarly high case numbers $[1,2]$.

Lessons learned from COVID-19 in Turkey with detected needs for further investigation are as follows:

(1) The first 30-day practices have been in the form of a reactive response and have been successful to prevent the surge pressure on the healthcare system. Unfortunately, still high daily case numbers suggest potential pockets of hidden (asymptomatic) cases in the population, which would be a threat for a second wave upon relaxing the current preventive measures.

(2) At this phase, Turkey needs to expand its management strategies moving ahead of the infection in a proactive manner. This requires timely analysis and sharing of available national data and conducting epidemiologic field research to learn more about the overall burden of COVID-19, which is essential for effective management plans, tailored to local needs [6].

National data need to be analyzed in detail with regards to:

(a) Individual characteristics of COVID-19 cases: Socioeconomic characteristics; comorbidities; potential risk factors (e.g., obesity, smoking, crowded household, use of immunosuppressive drugs, etc.); origin of the infection; residential settings, contact rates. 
Table 1 List of public measures for mitigating COVID-19 in Turkey

\begin{tabular}{|c|c|}
\hline Dates & $\begin{array}{l}\text { Important accomplishments/introduction of new } \\
\text { preventive measures }\end{array}$ \\
\hline Jan 22 & National Scientific Board meeting, risk assessment \\
\hline $\operatorname{Jan} 24$ & $\begin{array}{l}\text { National COVID-19 Guidelines, 14-day quarantine } \\
\text { for those arriving from China }\end{array}$ \\
\hline Feb 3 & All international flights to/from China stopped \\
\hline Feb 6 & $\begin{array}{l}\text { Use of thermal cameras at airports for all } \\
\text { international arrivals }\end{array}$ \\
\hline Feb 23 & $\begin{array}{l}\text { Closure of land borders with Iran, flights to/from } \\
\text { Iran were stopped }\end{array}$ \\
\hline Feb 29 & $\begin{array}{l}\text { All international flights to/from Italy, Spain and Iraq } \\
\text { stopped }\end{array}$ \\
\hline Mar 3 & 14-Day quarantine for those arriving from Saudi Arabia \\
\hline Mar 11 & $\begin{array}{l}\text { 14-Rules for all for preventing COVID- } 19 \text { (including } \\
\text { social distancing); restrictions to malls, public places, } \\
\text { recreational areas; stay-at-home advice for those } \\
\text { aged } \geq 65 \text { years }\end{array}$ \\
\hline Mar 16 & $\begin{array}{l}\text { Closure of schools; distance-learning at universities; all } \\
\text { international flights to/from Germany, France, Spain, } \\
\text { Norway, Denmark, Belgium, Austria, Sweden, Holland, } \\
\text { followed by England, Switzerland, Saudi Arabia, Egypt, } \\
\text { Ireland, United Arab Emirates were stopped }\end{array}$ \\
\hline Mar 21 & Obligatory stay-at-home for those aged $\geq 65$ years \\
\hline Mar 27 & $\begin{array}{l}\text { Restrictions expanded, administrative/judicial fines, } \\
\text { as needed }\end{array}$ \\
\hline Apr 4 & $\begin{array}{l}\text { Obligatory stay-at-home for those aged } \leq 20 \text { years; in/out } \\
\text { travel bans for } 31 \text { cities; compulsory use of masks for all } \\
\text { in public places }\end{array}$ \\
\hline Apr $11-12$ & Total lock-downs in 31 cities \\
\hline Apr $17-18$ & \\
\hline Apr 23-26 & \\
\hline
\end{tabular}

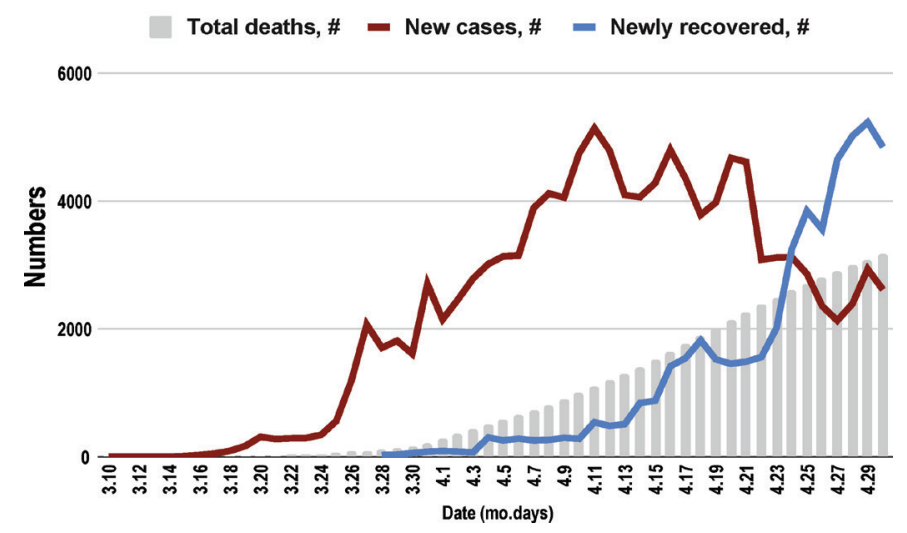

Figure $1 \mid$ Distribution of COVID-19 cases and deaths in Turkey over time.

(b) Proportion of asymptomatic cases, characteristics of those individuals, information on their follow up and final outcomes.

(c) Characteristics of tests used besides polymerase chain reaction (PCR) tests, validity indices of the tests used, testing criteria, proportion of repeated test numbers.

(d) Details of hospitalizations, related care algorithms, effectiveness of various drugs/methods used, fatality rates and related factors. (e) Reportedly, 137,500 individuals have been quarantined in 180 several villages and neighborhoods in 52 (of total 81) cities by April 9, due to test positivity and/or unsatisfactory compliance with public measures [2]. Baseline and follow-up data from those need to be scrutinized to investigate test positivity, percentage of asymptomatic cases, transmission probabilities, outcomes and related risk factors, if possible.

(f) Increasing the test numbers to 30,000 per day [2] over the first 30 days is praiseworthy, we will need even higher number of testing in transition to normalization. With relaxation of the public measures, valid antibody tests will be needed for confirming readiness of those recovered to return daily routines; to identify infection risk of those working at frontline (such as, health care workers); or, seroprevalence rates in selected populations. At national level, all diagnostic and screening tests need to be validated $[7,8]$.

(g) Detailed documentation of the contact-tracing is needed, to evaluate its effectiveness to mitigate case numbers, together with its feasibility (re: manpower and cost). Potential increase in case numbers upon relaxation of public restrictions will require timely and effective contact-tracing. Thus, this information should be useful for revisions of the related protocols, if needed.

(3) Nationwide closure of schools, businesses, stay-at-home practices seem to be decreasing the new cases. However, assessment of comparative effectiveness of public measures through research with estimation of transmission probabilities, contact rates, and proportion of asymptomatic cases in the community and/or repeated effective reproduction number calculations will be necessary $[6,9]$.

In summary, we have learned that while clinicians are taking care of COVID-19 cases in the hospitals, epidemiological studies must be initiated concomitantly in the communities. Although it may seem to be time-consuming and costly, use of serological tests in the field integrated with well-defined active surveillance studies will enable scientific, robust, data-driven recommendations for quarantine further or sustain the shelter-in-place orders [6].

For better understanding, efficient control, and reliable forecasting of COVID-19 pandemic at this stage in Turkey, and possibly earlier in countries with currently low numbers, below is a recommended epidemiologic investigation framework. Six specific research topics are proposed, with alternative study designs suitable for each:

1. Detection of total number of COVID-19 cases, percentage of asymptomatic cases, estimation of active cases in the population

Serosurveys of representative communities.

Serosurveys of high-risk cohorts such as health professionals, closed communities.

2. Detection of personal risk factors for infection or related death

Community surveys.

Case-control studies nested in hospitalized patients.

Community-based cohorts. 
3. Detection of contact rate

Contact-tracing activities.

Household cohorts.

Household transmission studies.

4. Detection of transmission probabilities

Household transmission studies.

Studies integrated into contact-tracing activities.

Household cohorts.

5. Detection of exact case-fatality rate

Hospitalized/ICU case series.

Electronic follow up of serosurveyed communities over time (through electronic health records/hospital/insurance records).

6. Evaluation of compliance with/effectiveness of various preventive measures

Community surveys.

Follow up of quarantined individuals

Calculation of case/death doubling times and $R_{0} / R_{e}$ estimations.

Electronic/digital tracing of population movements.

Use of geographic information systems in different regions [6].

Turkey has been successful so far, yet, is only in the beginning of the epidemic. Flattening of the epidemic curve does not mean it is over yet; it just confirms the current efforts are working. In a population of 83 million, due to differences in residential settings, behavioral patterns, social and work conditions, future public measures/interventions may require modifications for subpopulations [10]. Thus, local besides national studies are clearly warranted. Collaborative and co-ordinated efforts are essential among officials, multidisciplinary professional groups, and international agencies for evidence-based epidemic response practices to control COVID-19 effectively in Turkey and all over the world.

\section{CONFLICTS OF INTEREST}

The author declares no conflicts of interest.

\section{REFERENCES}

[1] Johns Hopkins University and Medicine (JHUM). Coronavirus Resource Center. Dashboard by the Center for Systems Science and Engineering; 2020. Available at: https://coronavirus.jhu.edu/ map.html.

[2] Ministry of Health, Republic of Turkey (MoH-TR). COVID-19 web page of the Republic of Turkey, Ministry of Health. Available at: https://covid19.saglik.gov.tr [Internet].

[3] World Health Organization (WHO). Coronavirus disease 2019 (COVID-19). Situation Report - 101. Available at: https://www.who. int/docs/default-source/coronaviruse/situation-reports/20200430sitrep-101-covid-19.pdf?sfvrsn=2ba4e093_2 [Internet].

[4] Public Announcement of the Ministry of Health, Turkey in the Coronavirus session at the Grand National Assembly on March 19, 2020. Available at: https://www.dw.com/tr/koca-yogun-bakim-yatak-durumunda-sansliyiz/a-52838104.

[5] Kılıç AU, Kara F, Alp E, Doganay M. New threat: 2019 novel Coronavirus infection and infection control perspective in Turkey. North Clin Istanb 2020;7;95-8.

[6] Lipsitch M, Swerdlow DL, Finelli L. Defining the epidemiology of COVID-19 - Studies needed. N Engl J Med 2020;382;1194-6.

[7] Stadlbauer D, Amanat F, Chromikova V, Jiang K, Strohmeier S, Arunkumar GA, et al. SARS-CoV-2 Seroconversion in humans: a detailed protocol for a serological assay, antigen production, and test setup. Curr Protoc Microbiol 2020;57;e100.

[8] Li Z, Yi Y, Luo X, Xiong N, Liu Y, Li S, et al. Development and clinical application of a rapid IgM-IgG combined antibody test for SARS-CoV-2 infection diagnosis. J Med Virol 2020;1-7.

[9] Day M. Covid-19: four fifths of cases are asymptomatic, China figures indicate. BMJ 2020;369;m1375.

[10] TUIK-TR. Address-based population records system. Turkish Institute of Statistics. News Bulletin; 2019, Number: 33705. Available at: http://www.tuik.gov.tr [Internet]. 